\title{
An Updated Analytical Structural Pounding Force Model Based on Viscoelasticity of Materials
}

\author{
Qichao Xue, ${ }^{1}$ Chunwei Zhang, ${ }^{2}$ Jian He, ${ }^{1}$ Guangping Zou, ${ }^{1}$ and Jingcai Zhang ${ }^{1}$ \\ ${ }^{1}$ College of Aerospace and Civil Engineering, Harbin Engineering University, Harbin, China \\ ${ }^{2}$ Institute for Infrastructure Engineering, Western Sydney University, Sydney, NSW, Australia \\ Correspondence should be addressed to Chunwei Zhang; chunwei.zhang@westernsydney.edu.au
}

Received 5 May 2016; Revised 31 July 2016; Accepted 3 August 2016

Academic Editor: Londono Monsalve

Copyright (c) 2016 Qichao Xue et al. This is an open access article distributed under the Creative Commons Attribution License, which permits unrestricted use, distribution, and reproduction in any medium, provided the original work is properly cited.

\begin{abstract}
Based on the summary of existing pounding force analytical models, an updated pounding force analysis method is proposed by introducing viscoelastic constitutive model and contact mechanics method. Traditional Kelvin viscoelastic pounding force model can be expanded to 3-parameter linear viscoelastic model by separating classic pounding model parameters into geometry parameters and viscoelastic material parameters. Two existing pounding examples, the poundings of steel-to-steel and concrete-toconcrete, are recalculated by utilizing the proposed method. Afterwards, the calculation results are compared with other pounding force models. The results show certain accuracy in proposed model. The relative normalized errors of steel-to-steel and concreteto-concrete experiments are $19.8 \%$ and $12.5 \%$, respectively. Furthermore, a steel-to-polymer pounding example is calculated, and the application of the proposed method in vibration control analysis for pounding tuned mass damper (TMD) is simulated consequently. However, due to insufficient experiment details, the proposed model can only give a rough trend for both single pounding process and vibration control process. Regardless of the cheerful prospect, the study in this paper is only the first step of pounding force calculation. It still needs a more careful assessment of the model performance, especially in the presence of inelastic response.
\end{abstract}

\section{Introduction}

Earthquakes may lead to damage and collapse of colliding structures in the case of insufficient gap between adjacent structures. This damage caused by pounding effect has been observed in both adjacent tall buildings and long bridges in all major earthquakes [1-5]. In many cases, these earthquakeinduced poundings may cause functionality to be disabled or even more serious results, such as large plastic deformations and splintering and collapse of main structural components of buildings. For bridges girder, dislocations or fallings may occur due to vertical or horizontal poundings [6].

Illustrating the pounding forces between colliding bodies precisely is the basis of simulating pounding process. Numerous literatures have focused on analysing structures of earthquake-induced pounding. Some research [7-11] involves poundings between adjacent buildings. For example, Jankowski [7] analysed the parametric pounding of two buildings with the same number of stories. Based on Jankowski's nonlinear viscoelastic analytical model, Pratesi et al. [8] developed a special multilink viscoelastic finite element contact model and analysed seismic pounding of a slender reinforced concrete bell tower. Shakya and Wijeyewickrema [9] dealt with the seismic pounding between three typical reinforced concrete moment resisting frame buildings in a row considering the effects of underlying soil on the structural response. Polycarpou and Komodromos [10] investigated the effects of potential pounding incidences on the seismic response of a typical seismically isolated building through numerical simulations. Ye et al. [11] utilized a modified Kelvin impact model to investigate the behavior of the base-isolated building pounding.

More literatures focus on solving the bridges pounding problems. Cui et al. [12] utilized Kelvin model to simulate the pounding between two adjacent highway bridges with expansion joints. Yang and Yin [13] developed a theoretical 
approach to investigate the transient behavior of continuous bridges under near-fault vertical ground motions. Dimitrakopoulos [14] proposed a novel nonsmooth rigid body approach so as to analyse the seismic response of pounding skew bridges which involve obliquely frictional multiplecontact phenomena.

At the same time, it has been found that soil-structure interactions in structures are critical in earthquake-pounding problems [15-18]. However, regardless of structures or pounding types, the definition of interactions between two colliding bodies, which is called pounding force models, is necessary and predominant in analysis.

This paper briefly reviews the analytical impact/pounding models firstly. Moreover, an updated pounding force analytical method is proposed by introducing viscoelastic constitutive model and contact mechanics analysis method. Afterwards, two existing pounding examples, the poundings of steel-to-steel and concrete-to-concrete, are recalculated by utilizing the above proposed method and further compared with other pounding force models. The parametric study and feasibility of the proposed model are discussed consequently. Furthermore, this paper calculates a steel-to-polymer pounding example and simulates the application of pounding TMD in vibration control based on the method proposed above. The study here presents only the first step of pounding force calculation. Therefore, it is necessary to carry out more careful assessments of the model performance.

\section{Review of Existing Pounding Force Models}

Due to the complexity and nonlinearity associated with colliding process, including inelasticity, plasticity, viscoelasticity, frictions, and multiple forms of energy dissipation, many simplified pounding force models have been proposed to calculate, simulate, and represent the force responses between colliding bodies.

Several pounding force models have been proposed to calculate the interaction between pounding structures. All these models are on the basis of stereomechanics which is a classic theory of impact. It is based on the laws of conservation of energy and momentum by neglecting the details of impact process. The energy dissipation during the pounding process is dependent on the differences between approaching and separative velocities of colliding bodies (Figure 1).

Figure 1 is the sketch of classical colliding process, in which $m_{1}$ and $m_{2}$ are the masses of the two colliding bodies, $V_{1}$ and $V_{2}$ are velocities before colliding, and $V_{1}^{\prime}$ and $V_{2}^{\prime}$ are velocities after colliding corresponding to $m_{1}$ and $m_{2}$. Parameter $e$ is defined as

$$
e=\frac{V_{2}^{\prime}-V_{1}^{\prime}}{V_{1}-V_{2}}
$$

The velocity of the colliding bodies after collision and energy loss during the colliding process can be illustrated based on parameter $e$ and velocities before collision:

$$
V_{1}^{\prime}=V_{1}-(1+e) \frac{m_{2} V_{1}-m_{2} V_{2}}{m_{1}+m_{2}}
$$

$$
V_{2}^{\prime}=V_{2}-(1+e) \frac{m_{1} V_{1}-m_{2} V_{2}}{m_{1}+m_{2}},
$$

$\Delta E$

$$
=\frac{1}{2}(1+e) \frac{m_{1} m_{2}}{m_{1}+m_{2}}\left(V_{1}-V_{2}\right)\left(V_{1}-V_{2}+V_{2}^{\prime}-V_{1}^{\prime}\right),
$$

where $\Delta E$ is energy dissipation in the pounding process due to the high frequency vibration, heat, and noise. Interactions between two colliding bodies in approaching process and restitution process are ignored under traditional colliding theory. The only parameter to be verified in colliding process is parameter $e$, which varies from different colliding materials. It can be determined by colliding experiments.

When the transient effects of poundings need to be considered in certain structures under dynamic loads, the time history of pounding forces between two colliding bodies is necessary. A precise pounding force model developed to illustrate pounding process is the key aspect in analysis. Most existing pounding force models are based on classical theory of impact, showing advantages in analysing multiple bodies colliding and structure poundings under seismic loads. The following several types of models are still popular in seismic analysis.

2.1. Linear Spring Model. Linear spring model, which is based on classical theory of impact, considers the interaction between two colliding bodies as a linear spring (Figure 2(a)). It is only effective in rigid and plan-to-plan collision. The force during the collision can be illustrated as follows:

$$
F(t)=k_{S} \delta(t)
$$

where $k_{S}$ is the parameter determined by material elasticity and spring stiffness shown in Figure $2(\mathrm{a}) ; \delta(t)$ is the relative displacement between two colliding bodies. Ruangrassamee and Kawashima [21] utilized the linear spring model to calculate the pounding of bridge decks with multiple variable dampers. Wang and Shih [6] presented a case study of the sliding for bridge decks and pounding at abutment-backfill by utilizing a linear spring model.

2.2. Nonlinear Spring Model (Hertz Spring Model). Nonlinear spring model, also called Hertz spring model, is based on static contact mechanics. It is initially introduced into analysis for collision process by Goldsmit [22]. This model is extremely effective in elastic poundings and suitable for curved surface contacts with different curvatures. The pounding force can be regarded as a nonlinear spring between colliding bodies (Figure 2(b)) and it can be written as

$$
F(t)=k_{H} \delta(t)^{3 / 2},
$$

where $k_{H}$ is the Hertz pounding parameter determined by materials and contact geometries.

Many pounding analyses have utilized this model, which show the effectiveness for elastic poundings. Chau and Wei [23] modelled poundings between two adjacent structures 


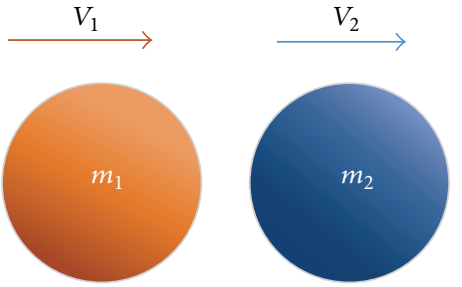

Before colliding

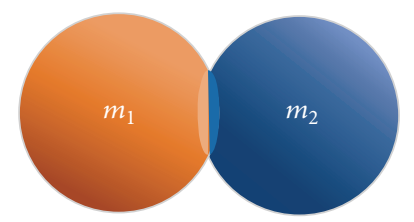

Colliding
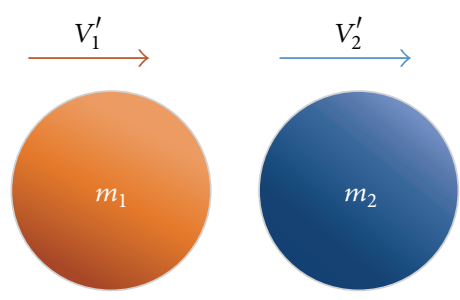

After colliding

FIGURE 1: Sketch of colliding process.

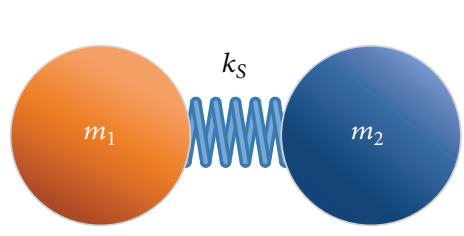

(a) Linear spring model

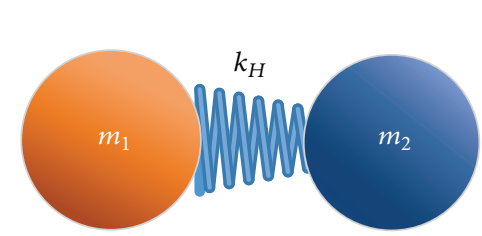

(b) Nonlinear spring model

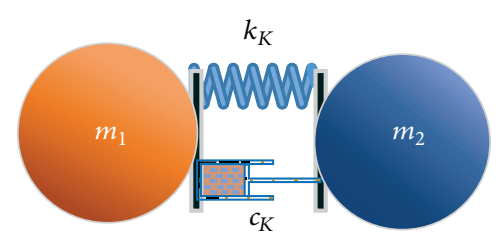

(c) Kelvin model

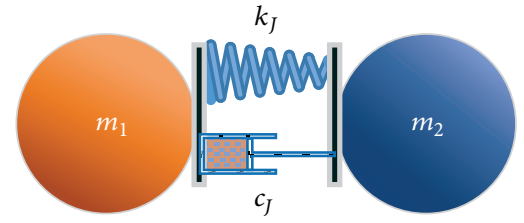

(d) Nonlinear spring model with damper (Jankowski [29])

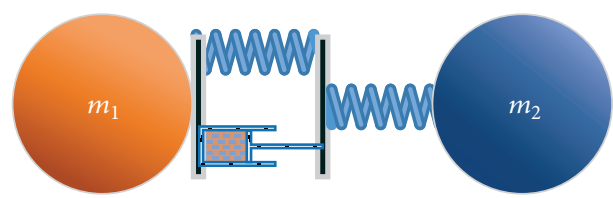

(e) Three-parameter model (proposed method)

Figure 2: Pounding force models.

by utilizing a nonlinear Hertz impact model, in which they simplified the structures as two single-degree-of-freedom oscillators. The results showed that maximum relative impact velocity was not very sensitive to changes in the contact parameters. Pantelides and $\mathrm{Ma}$ [24] adopted Hertz pounding model to study the effects of colliding on horizontal pounding of bridges for the first time. Due to lack of precise value of stiffness of impact, Cui et al. [12] calculated the poundings between bridges and deduced parameter $k_{H}$.

2.3. Kelvin Model. Kelvin model (Figure 2(c)) is a type of linear viscoelastic model that can deal with energy dissipation during collision deformation. Compared to linear spring model and Hertz nonlinear spring model, it can describe energy dissipation except for tension stress at the end of pounding process. This method was initially proposed and discussed by Anagnostopoulos [25, 26]. Kelvin model can be written as

$$
F(t)=k_{K} \delta(t)+c_{K} \dot{\delta}(t),
$$

where $k_{K}$ is the stiffness parameter of Kelvin model and $c_{K}$ is damping factor of damper in Kelvin model. (') means firstorder derivative to the time. According to Anagnostopoulos' work, $c_{K}$ is not an independent parameter but should be calculated on the basis of the masses of colliding bodies $m_{1}$ and $m_{2}$, stiffness $k_{K}$, and parameter $e$ :

$$
c_{K}=2 \xi \sqrt{k_{K}\left(\frac{m_{1} m_{2}}{m_{1}+m_{2}}\right)}
$$

with

$$
\xi=-\frac{\ln e}{\sqrt{\left[\pi^{2}+(\ln e)^{2}\right]}},
$$

where $k_{K}$ is determined by pounding experiment. Many literatures have utilized this model, which showed its effectiveness. Agarwal et al. [27] utilized the Kelvin model and investigated the earthquake-induced upper story pounding response of two buildings in close proximity with different base isolation systems. Shakya and Wijeyewickrema [9] utilized the Kelvin model to calculate the impact of two multistory buildings. Komodromos et al. [10, 28] utilized the Kelvin model to analyse the pounding between isolated buildings and foundations. Madani et al. [17] also utilized the Kelvin model to analyse the adjacent building poundings considering soil-structure interactions.

2.4. Nonlinear Viscoelastic Model. The nonlinear viscoelastic model (Figure 2(d)) is firstly developed by Jankowski based 
on Kelvin model [29, 30]. He constructed a segmental function to avoid the tension stress at the end of restitution period.

$$
\begin{aligned}
& F(t)=k_{J} \delta^{3 / 2}(t)+c_{J} \dot{\delta}(t) \\
& \text { for } \dot{\delta}(t)>0 \text { (approaching period), } \\
& F(t)=k_{J} \delta^{3 / 2}(t) \text { for } \dot{\delta}(t)<0 \text { (restitution period), }
\end{aligned}
$$

where $k_{J}$ is the impact stiffness parameter and $c_{J}$ is determined by the following formula:

$$
c_{J}=2 \xi_{J} \sqrt{k_{J} \sqrt{\delta(t)}\left(\frac{m_{1} m_{2}}{m_{1}+m_{2}}\right)}
$$

with

$$
\xi_{J}=\frac{\sqrt{5}}{2 \pi} \frac{1-e^{2}}{e} .
$$

Jankowski utilized this model to calculate the poundings of multistory buildings [7] and isolated elevated bridges [31]. Pratesi et al. [8] proposed a special multiple-link viscoelastic finite element contact model which was deduced from Jankowski's nonlinear viscoelastic model.

2.5. Other Pounding Force Models. Previous literatures have proposed several other pounding models, most of which are revised on the basis of former models. Mahmoud [32] modified Kelvin model which was only activated during the approach period of collision. Khatiwada et al. [33] proposed the Hunt-Crossley model, which changed the power factor of relative displacement in Kelvin model from $3 / 2$ to variable $n$.

Based on the summarization of existing pounding models, only one dependent parameter in above pounding force models needs to be decided by experiments. This parameter contains much information including the masses of bodies, stiffness, pounding speed, and contact geometries. In engineering practice, the parameter will change with specific situations. Therefore, the parameter obtained from model test will meet limitation of utilization in reality. What is more, the power of penetration displacement will not change for each pounding force model separately: 1 for linear elastic model and 3/2 for nonlinear models. However, as for contact mechanics [34], the power number is determined by the geometry of contacting interface, which varies from 1 to 2 . In next section, an updated pounding force model will be developed to overcome the aforementioned disadvantages.

\section{Analysis Method}

The main idea of the proposed pounding force method in this paper is based on linear viscoelasticity of materials and law of contact mechanics. The author has tried to separate variables from pounding materials and contact geometries. The following assumptions should be observed:

(1) The transmogrification is small. All deformations during the pounding process are assumed as viscoelastic and tiny, which ignore higher order effects of deformation of pounding responses.
(2) The inertial effects of deforming part in pounding bodies are ignored. For pounding process of civil engineering structures, strain rate ranges from $10^{2} \mathrm{~s}^{-1}$ to $10^{4} \mathrm{~s}^{-1}$, and it can be classified as low velocity impact. Therefore, the inertial effect of deforming area can be ignored.

(3) The energy dissipation during pounding process only comes from the viscoelasticity of materials. This means that not only the traditional elastic material, such as steel and concrete, but also the real viscoelastic material, such as polymers, is considered as viscoelastic materials. This assumption is reasonable because the elasticity modulus of most elastic materials has rate-dependent properties. Furthermore, a viscoelastic constitution model can be degenerated to an elastic model in a certain case.

3.1. Viscoelastic Material Constitutive Models. Viscoelasticity of material can be illustrated by linear constitution models, which are composed of springs and dash-pots. The simplest linear constitutive models are Maxwell model and Kelvin model, which are characterized by the fluid properties and solid properties of viscoelastic material (as shown in Figures 3(a) and 3(b)). More complicated model such as 3-parameter solid model (as shown in Figure 3(c)) is more accurate in illustrating the behavior of viscoelasticity.

Kelvin viscoelastic constitution model can be written in a differential type:

$$
\sigma=q_{0} \varepsilon+q_{1} \dot{\varepsilon} \quad \text { with } q_{0}=E_{1}, q_{1}=C_{1},
$$

where $\sigma$ and $\varepsilon$ are stress and strain, respectively; $E_{1}$ and $C_{1}$ are the spring parameter and dash-pot parameter in constitutive model; $q_{0}$ and $q_{1}$ are parameters to determine the constitutive model in Figure 3(a).

For 3-parameter solid viscoelastic model (Figure 3(b)), it can be written as

$$
\begin{aligned}
& \sigma+p_{1} \dot{\sigma}=q_{0} \varepsilon+q_{1} \dot{\varepsilon} \\
& \quad \text { with } p_{1}=\frac{C_{1}}{E_{1}+E_{2}}, q_{0}=\frac{E_{1} E_{1}}{E_{1}+E_{2}}, q_{1}=\frac{C_{1} E_{2}}{E_{1}+E_{2}},
\end{aligned}
$$

where $E_{1}, E_{2}$, and $C_{1}$ are the spring parameters and dashpot parameter in 3-parameter constitutive model; $q_{0}, q_{1}$, and $q_{2}$ are parameters to determine the constitutive model in Figure 3(b).

Regardless of the complexity of the constitutive models, if they are composed of springs and dash-pots in series or parallel relations (Figure 3(c)), they can be written as following differential equation:

$$
p_{0} \sigma+p_{1} \dot{\sigma}+p_{1} \ddot{\sigma}+\cdots=q_{0} \varepsilon+q_{1} \dot{\varepsilon}+q_{1} \ddot{\varepsilon}+\cdots .
$$

The equation can be written as

$$
P \sigma=Q \varepsilon
$$

where $P$ and $Q$ are differential operators. Laplace transformations are introduced to both sides of the equation, and the expression in Laplace domain can be obtained:

$$
\bar{P}(s) \bar{\sigma}(s)=\bar{Q}(s) \bar{\varepsilon}(s),
$$




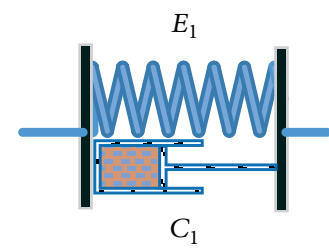

(a) Kelvin model

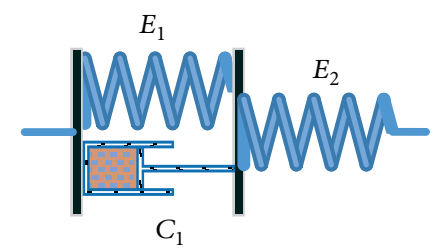

(b) Three-parameter model

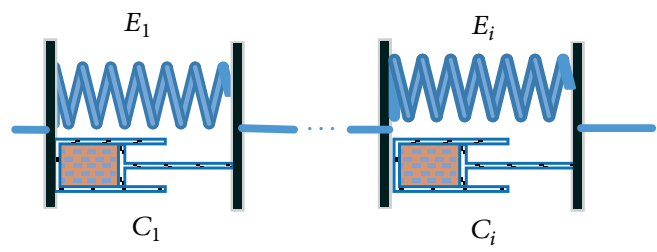

(c) Other linear viscoelastic models

FIGURE 3: Linear viscoelastic constitutive models.

TABLE 1: Expressions and descriptions of parameters.

\begin{tabular}{|c|c|c|c|c|}
\hline Contact cases & $D(A, R, l)$ & $E^{*}$ & $\alpha$ & Parameter description \\
\hline $\begin{array}{l}\text { Polyhedral } \\
\text { cylinder-to-rigid plane }\end{array}$ & $\frac{A}{l}$ & $E$ & 1 & $\begin{array}{c}A \text { and } l \text { are contact area and } \\
\text { height of cylinder }\end{array}$ \\
\hline Thin plate-to-rigid plane & $\frac{A}{l}$ & $\frac{E(1-v)}{(1+v)(1-2 v)}$ & 1 & $\begin{array}{c}A \text { and } l \text { are contact area and } \\
\text { thickness of plate }\end{array}$ \\
\hline $\begin{array}{l}\text { Rigid cylinder-to-elastic } \\
\text { plane }\end{array}$ & $2 R$ & $\frac{E}{1-v^{2}}$ & 1 & $R$ is the radius of cylinder \\
\hline $\begin{array}{l}\text { Rigid sphere-to-elastic } \\
\text { plane }\end{array}$ & $\frac{4}{3} R^{1 / 2}$ & $\frac{E}{1-v^{2}}$ & $\frac{3}{2}$ & $R$ is the radius of sphere \\
\hline $\begin{array}{l}\text { Rigid cylinder-to-elastic } \\
\text { plane (curvature surface } \\
\text { contact) }\end{array}$ & $\frac{\pi}{4} l$ & $\frac{E}{1-v^{2}}$ & 1 & $l$ is the height of cylinder \\
\hline Rigid cone-to-elastic plane & $\frac{2}{\pi \tan \theta}$ & $E$ & 2 & $\theta$ is the angle of cone \\
\hline $\begin{array}{l}\text { Elastic curvature } \\
\text { surface-to-elastic curvature } \\
\text { surface }\end{array}$ & $\frac{4}{3}\left(\frac{R_{a} R_{b}}{R_{a}+R_{b}}\right)^{1 / 2}$ & $\frac{1}{\left(1-v_{a}^{2}\right) / E_{a}+\left(1-v_{b}^{2}\right) / E_{b}}$ & $\frac{3}{2}$ & $\begin{array}{c}R_{a} \text { and } R_{b} \text { are radius of two } \\
\text { contact surface }\end{array}$ \\
\hline $\begin{array}{l}\text { Elastic cylinder-to-elastic } \\
\text { cylinder (parallel contact) }\end{array}$ & $\frac{\pi}{4} l$ & $\frac{1}{\left(1-v_{a}^{2}\right) / E_{a}+\left(1-v_{b}^{2}\right) / E_{b}}$ & 1 & $l$ is the height of cylinder \\
\hline
\end{tabular}

where $\bar{P}(s)$ and $\bar{Q}(s)$ are no more differential operators but polynomials of parameter $s .(\overline{)})$ represents the Laplace transformation. Thus, the modulus of elasticity for viscoelastic material in Laplace domain can be defined as

$$
\frac{\bar{\sigma}(s)}{\bar{\varepsilon}(s)}=\frac{\bar{Q}(s)}{\bar{P}(s)}=\bar{E}(s) .
$$

3.2. Process of Analysis. Based on the former analysis, all pounding force models can be written in the following form:

$$
F_{p}=D(A, R, l) \cdot E^{*} \cdot \delta^{\alpha}
$$

where $D(A, R, l)$ is the function of contact geometry of colliding bodies, which can be represented by contact area $A$, surface radius $R$, or the height of contact bodies $l$. Table 1 shows the illustrative examples of (17) based on contact mechanics. $E^{*}$ is the parameter related to material properties of contact bodies, which may contain the moduli of elasticity for both bodies, such as $E_{1}$ and $E_{2}$ as well as Poisson's ratios $v_{1}$ and $v_{2}$. Parameter $\delta$ is the function of penetration displacements. The power number $\alpha$ depends on the shape of contact geometry. In complicated contact pounding cases, such as discontinuous interfaces or noncentral collision, there are no explicit expressions to illustrate the relation between pounding force and penetration displacements. Even for the simplified pounding model with regular pounding interfaces, the constitutive model of viscoelasticity also has no explicit expressions except for some special simple models, such as Kelvin model and Maxwell model.

The above expressions are constructed by elastic mechanics. In the case that the pounding bodies possess the properties with viscoelasticity, the following expression in Laplace domain can be achieved according to the principle of correspondence:

$$
\overline{F_{p}}=\bar{D}(A, R, l) \cdot \overline{E(s)^{*}} \cdot \overline{\delta^{\alpha}} \text {. }
$$

Since parameter $D(A, R, l)$ is a time-independent function, the inverse Laplace transformation of the above equation can be obtained:

$$
F_{p}(t)=D(A, R, l) \cdot \mathscr{L}^{-1}\left(E^{*}(s)\right) \cdot \delta(s)^{\alpha} \text {. }
$$

This represents the relationship between pounding force and contact displacement, which contains the implicit expression of inverse Laplace transformation $\mathscr{L}^{-1}()$. In most cases, it cannot be calculated directly except for some specially simplified cases. For material whose properties can be described as a linear viscoelastic constitutive model, there is no need to 


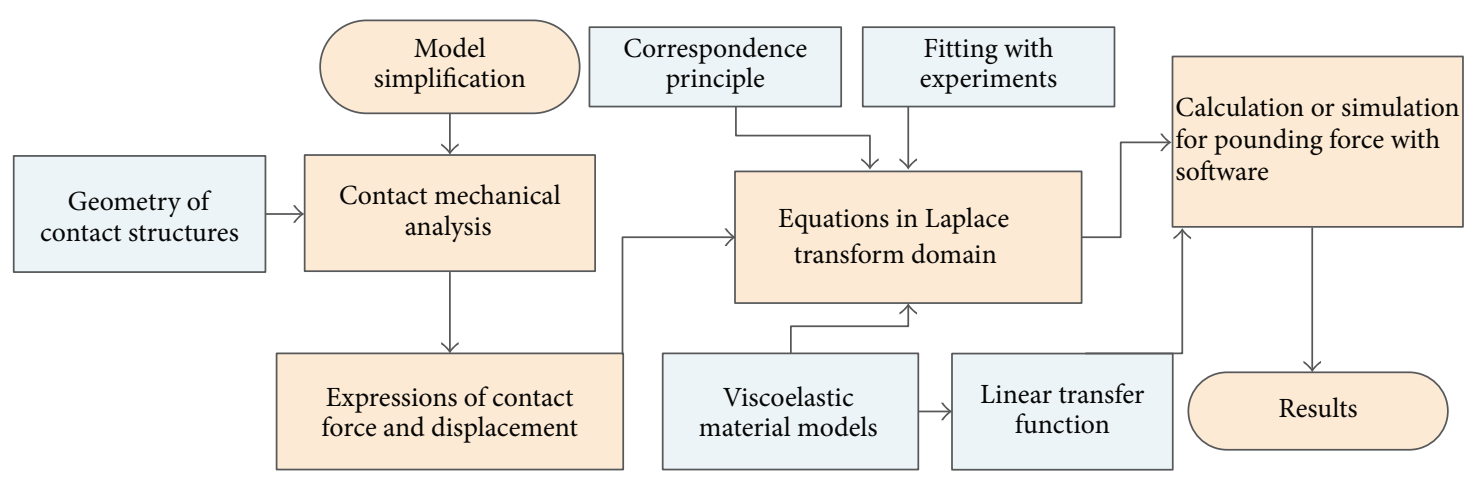

FIGURE 4: Sketch of the proposed pounding force analysis model.

obtain the explicit expression of Laplace inverse transformation, because it can be replaced by transfer function, which is a popular and common instrument in commercial simulation software. Therefore, it could be utilized to represent the pounding force directly in analysis.

According to the above analysis, the whole process in which the pounding force model will be determined is shown in Figure 4. When the pounding force between two colliding bodies is analysed, the first step is to obtain the suitable analysis model (elastic or viscoelastic) through contact geometry simplification. Afterwards, the simple expressions between contact force and displacement can be derived based on contact mechanics. The explicit expressions in Laplace domain can be obtained according to the principle of correspondence in viscoelastic mechanics. By fitting with the experimental curve, the parameters of pounding materials can be determined. Finally, the expressions of pounding force and pounding displacement can be achieved through Laplace inverse transformation. If the expression is implicit, parameter simplification or numerical Laplace inverse transformation can be carried out in simulation or calculation process. In this paper, only a linear 3-parameter solid linear viscoelastic model is utilized to verify the effectiveness of the proposed method.

\section{Model Verification}

Two classic collision examples are analysed in order to verify the accuracy of the proposed method. In both examples, a 3-parameter viscoelastic model (linear solid) will be utilized to construct pounding force model. The results will be compared with the experiments and the classic models in literature $[29,30]$. At same time, parametric study of the 3parameter model which influences the shape of pounding force-time history will be developed. The difference between the experimental results and the proposed model has been assessed by evaluating the following normalized error:

$$
\text { error }=\frac{\|F(t)-\overline{\bar{F}}(t)\|}{\overline{\bar{F}}(t)},
$$

where $\overline{\bar{F}}(t)$ is the collision force obtained by the existing experiments and $F(t)$ is time history response of numerical

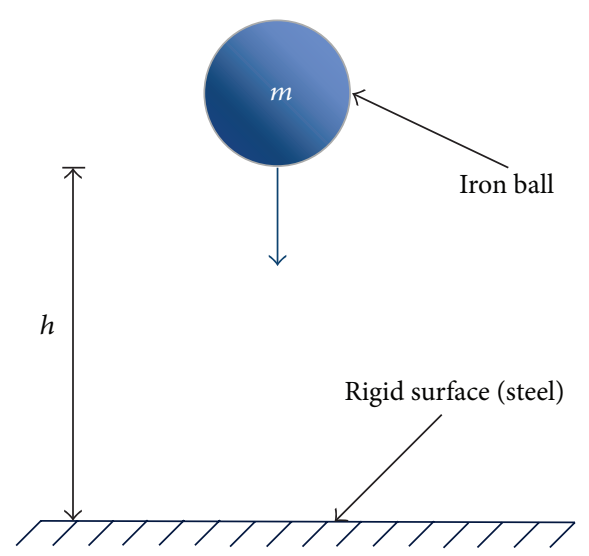

Figure 5: Model of a ball falling on a stationary rigid surface [19].

calculation or simulation results. $\|F(t)-\overline{\bar{F}}(t)\|$ is a Euclidean norm of $F(t)-\overline{\bar{F}}(t)$, and it can be calculated by a formula in discrete form. A total of 201 points for each curve in equivalent time space will be taken into account to calculate the error:

$$
\|F(t)-\overline{\bar{F}}(t)\|=\sqrt{\sum_{i=1}^{n}(F(t)-\overline{\bar{F}}(t))^{2}}, \quad n=201,
$$

where $n=201$ means that there are 200 equal intervals along the time axis which begin from time 0 and have the same ending time. According to (21), the values of these 201 discrete points will be calculated to determine the errors of curves. Although more discrete points can generate more precise error results, 201 points corresponding to 200 equal intervals are enough to guarantee the accuracy.

4.1. Steel-to-Steel Impact. The first example was carried out by Goland et al. [19] who dropped an iron ball onto the rigid surface (Figure 5) and measured pounding force changing with time. According to the assumptions above, although steel ball and rigid surface maintain elastic state in the whole pounding process, energy dissipation has occurred. Therefore, 3-parameter solid constitutive model is utilized to calculate the pounding force during collision. This does not 
mean that the steel is a typical viscoelastic material. It is aimed at obtaining the energy dissipation during the collision.

According to contact mechanics, the following equations could be obtained to illustrate the pounding force for collision between ball and surface:

$$
F_{c}=\frac{4}{3} R^{1 / 2} E^{*} \delta^{3 / 2},
$$

where $R$ is the radius of the ball and $E^{*}$ has the same expression as given in Table 1. Since the rigid surface is also made of steel, $E_{a}=E_{b}=E_{s}$ and $v_{a}=v_{b}=v_{s}$ can be obtained according to the expression of "elastic curvature surface-toelastic curvature surface" in Table 1. The following expression of $E^{*}$ can be derived:

$$
\begin{aligned}
E^{*} & =\frac{1}{\left(1-v_{1}^{2}\right) / E_{1}+\left(1-v_{2}^{2}\right) / E_{2}}=\frac{1}{2\left(\left(1-v_{s}^{2}\right) / E_{s}\right)} \\
& =\frac{E_{s}}{2\left(1-v_{s}^{2}\right)} .
\end{aligned}
$$

The modulus of elasticity for steel $E_{s}$ is $2.0 \times 10^{11} \mathrm{~Pa}$, and Poisson's ratio $v_{s}$ is 0.23 . There are three parameters in 3-parameter viscoelastic model: $E_{1}, E_{2}$, and $C_{1}$. Therefore, another two parameters can be defined to illustrate the relationship between them:

$$
\begin{aligned}
& R_{1}=\frac{E_{2}}{E_{1}}, \\
& R_{2}=\frac{C_{1}}{E_{1}} .
\end{aligned}
$$

In order to constrain the number of parameters, it is assumed that the 3-parameter viscoelastic model can be downgraded to the elastic model when the load is applied to the material in absolute static force. This means that if the existence of dash-pot is ignored, two springs in series $\left(E_{1}\right.$ and $E_{2}$ ) in the model perform the same value with the modules of elasticity in static state $E_{0}$. In this way, three parameters will be reduced to two parameters. This means that, in this static state of this example,

$$
E_{0}=\frac{E_{1} E_{2}}{E_{1}+E_{2}}=E^{*}=1.05 \times 10^{11} \mathrm{~Pa} .
$$

The diameter of the ball is $5 / 32$ inches and the height of dropping distance is 2 inches. Since there are at least two parameters to be determined in the pounding force model proposed in this paper, the minimum error will be optimized in the case that the peak value is same with the experimental result. The information of the optimization process is shown as follows:

$$
\text { Optimizing variable: } R=\left[R_{1}, R_{2}\right] \text {. }
$$

$$
\text { Constrain condition: } \max \quad(F(t))=80.3 \mathrm{~N}
$$

min error

From (24) and (25), parameters $R_{1}$ and $R_{2}$ are independent of one another. According to parametric study

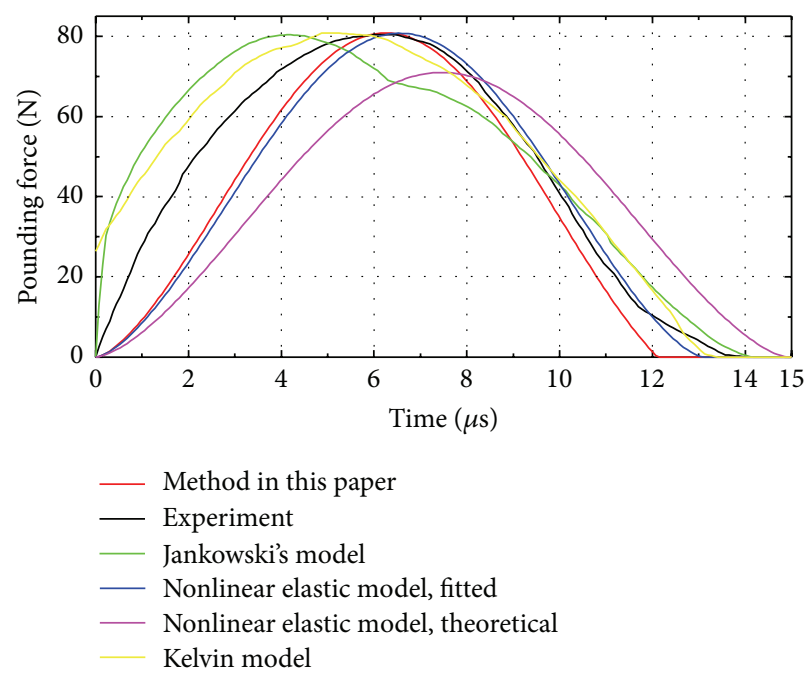

FIGURE 6: Time histories of pounding force of the steel ball dropping onto a rigid surface.

shown later, $R_{1}$ is mainly related with the height of the curve without changing areas surrounded by curve, and $R_{2}$ only affects the peak value in a limited range. Therefore, the optimization process is relatively easy and can be carried out by manual adjustment. In this way, the parameters of linear viscoelasticity can be determined.

Figure 6 shows the comparison results of impact forcetime history among the methods proposed in this paper and other existing pounding models. Based on the comparison, the proposed model, Kelvin model, Jankowski's model [29], and the nonlinear elastic model are fitted by the same peak value with experimental results, in which the curve of the proposed model is obtained by optimizing the error through (23). The pink curve, namely, the nonlinear elastic model, (theoretical) is based on theoretical calculation through (4), where value $k_{H}$ is determined in Table 1 .

The red curve corresponds to the proposed model, where the optimized value of $R_{1}$ is 0.46 and $R_{2}$ is 0.02 . It is found that it shows little difference with the experimental result in the descending part. The time corresponding to the peak value of pounding force is exactly the same with experimental results, which is at about $6.23 \mu \mathrm{s}$. The nonlinear elastic model result (pink curve, being not fitted with peak value), which is calculated theoretically through (4), has similar shape to the curve of the proposed model except for the peak value of $71.0 \mathrm{~N}$ and the time duration. After fitting the nonlinear elastic model with experimental results in the same peak value, the fitted curve (blue curve) is almost coincident with the proposed curve in this paper. This is because the pounding process for dropping iron ball is an elastic colliding process. $R_{2}=0.02$ in the proposed model is so "large" to make the calculating model "rigid" enough to perform as an elastic body. Actually, due to the calculation and parametric study in next section, when parameter $R_{2}$ is larger than $2 \times$ $10^{-4}$, parameter $R_{2}$ will not influence the curve shape.

The relative error of the proposed model in this paper is $19.8 \%$ as compared with nonlinear elastic model which 


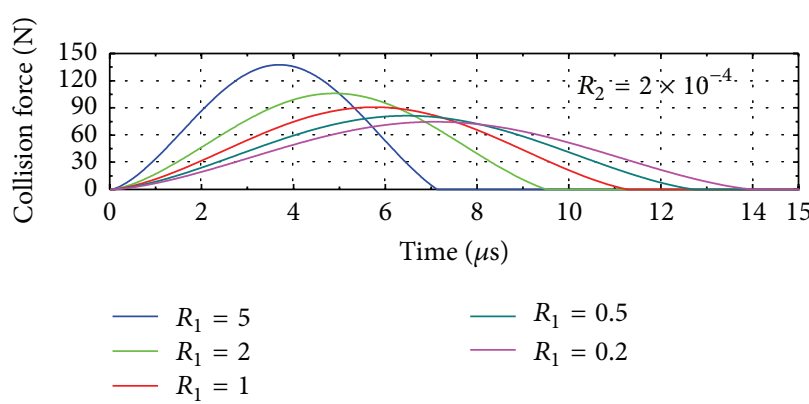

(a) Collision force in different parameters of $R_{1}$ with $R_{2}=2 \times 10^{-4}$

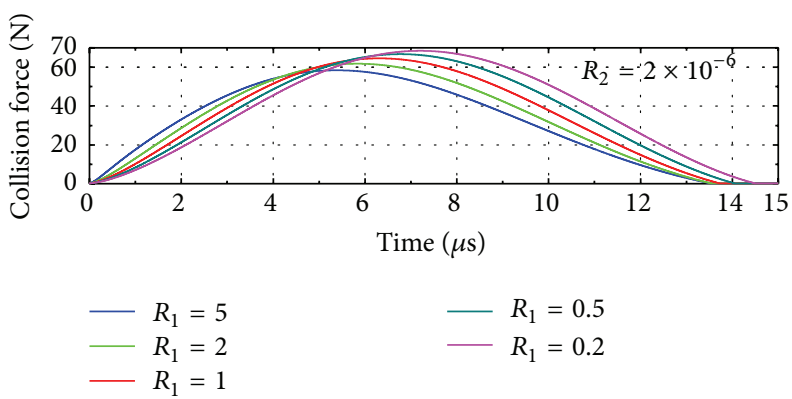

(c) Collision force in different parameters of $R_{1}$ with $R_{2}=2 \times 10^{-6}$

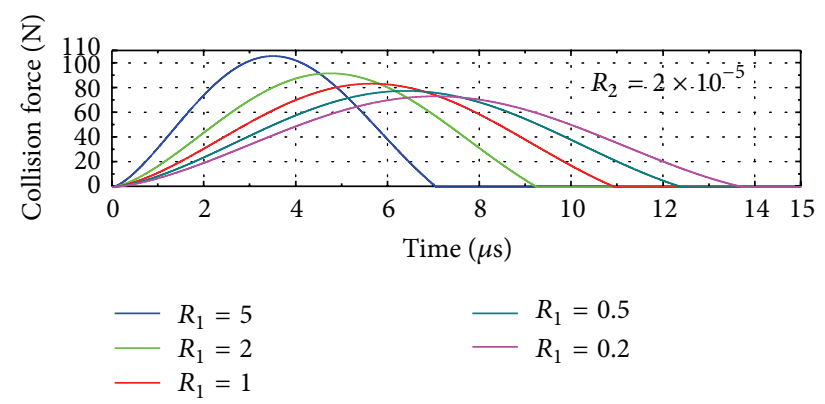

(b) Collision force in different parameters of $R_{1}$ with $R_{2}=2 \times 10^{-5}$

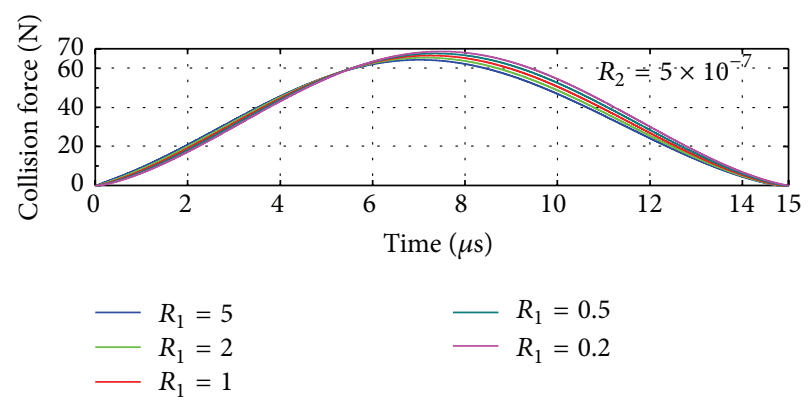

(d) Collision force in different parameters of $R_{1}$ with $R_{2}=5 \times 10^{-7}$

FIGURE 7: Collision force influenced by parameters of $R_{1}$ with different $R_{2}$.

is $19.6 \%$. There is only a little gap between them. This means that the nonlinear elastic model (peak value fitted) is precise enough for the case of steel-steel colliding. This is also in accordance with the fact that elasticity is the main property of steel material when the viscoelasticity is ignored. When the elasticity takes the dominant position, the proposed viscoelastic model will be degenerated into elastic model. The relative errors of Jankowski's model, Kelvin model (yellow curve), and nonlinear elastic model (theoretically) are $21.3 \%, 15.3 \%$, and $35.0 \%$, respectively. The total acting time of the model proposed in this paper is about $12 \mu \mathrm{s}$, and the experimental time is $14 \mu \mathrm{s}$.

4.2. Parametric Study of the Proposed Model. The proposed model is based on three-parameter viscoelastic constitutive model, but only two parameters are mutually independent according to the assumptions above. In order to study the influences of the two parameters, different curves with different parameters are calculated and plotted as shown in Figure 7.

The influences of $R_{1}$ are shown in Figure 7, in which $R_{1}$ changes as $5,2,1,0.5$, and $0.2 . R_{2}$ is $2 \times 10^{-4}, 2 \times 10^{-5}, 2$ $\times 10^{-6}$, and $2 \times 10^{-7}$, respectively. It can be concluded from Figure 7(a) that when $R_{1}$ increases from 0.2 to 5 , the peak value of pounding force will increase from $72 \mathrm{~N}$ to $142 \mathrm{~N}$. The pounding duration time also rises from $7.5 \mu \mathrm{s}$ to $14 \mu \mathrm{s}$. The shapes of curves are almost symmetric and all of these five curves have almost the same areas in terms of time-force axis represented curve, which means they have the same total impulse.

Figure 7(b) shows the collision forces in the case that $R_{2}=2 \times 10^{-5}$. The curves have similar changing trends and symmetry curve shapes to curves in Figure 7(a) in which $R_{1}$ decreases from 5 to 0.2 . When $R_{1}=5,2$, and 1 , the peak value decreases dramatically compared with the results in Figure 7 (a). However, for $R_{1}=0.5$ and 0.2 , both the peak value and the duration of the curves remain unchanged.

Figure $7(\mathrm{c})$ is corresponding to the case that $R_{2}=2 \times$ $10^{-6}$. The curves show a different variation tendency. When $R_{1}$ increases from 0.2 to 5 , the peak value of pounding force will decrease from $58 \mathrm{~N}$ to $69 \mathrm{~N}$. The curve shapes are no longer symmetric and the moment of peak value is not at the middle of the duration but moves forward to the forepart. Figure 7 (d) corresponds to the case that $R_{2}=2 \times 10^{-7}$. It can be seen that all the curves are almost coincident with pink curve $\left(R_{1}=0.2\right)$ in forepart of duration and only small gaps in second half. Also the curves are symmetric and similar to Figure 7(c).

Based on the comparison of these four graphs, it can be discovered that the shape and value of curves almost remain the same with parameter $R_{2}$ when $R_{1}$ is less than 0.2 . The larger $R_{1}$ is, the greater the variation amplitude will occur. What is more, it should be noted that when $R_{2}$ is large enough (larger than $2 \times 10^{-4}$ in this case), all curves have almost the same areas in terms of time-force axis, which means that they have the same total impulse. This proves that the pounding process is in almost elastic state, and the effect of dash-pot can be regarded as a rigid body in this pounding case. Spring $E_{1}$ which is in parallel with dash-pot in constitutive model is inoperative. Therefore, regardless of the variation of $R_{1}$, momentums of colliding bodies before and after collision remain unchanged. On the other hand, when $R_{2}$ is small enough (less than $5 \times 10^{-7}$ in this case), all curves tend to be coincidental. At this time, the dash-pot in constitutive model 


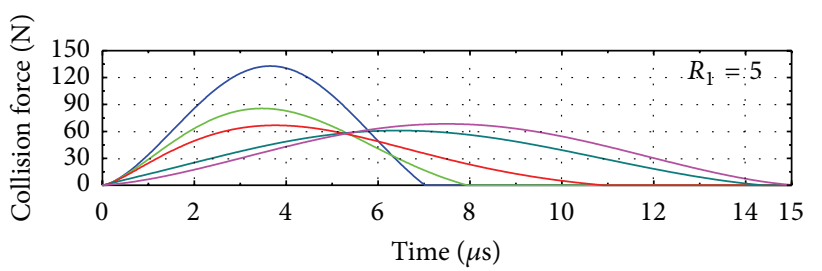

$$
\begin{array}{ll}
R_{2}=1 \times 10^{-4} \\
R_{2}=1 \times 10^{-5} \\
R_{2}=5 \times 10^{-6}
\end{array} \quad-\quad \begin{aligned}
& R_{2}=1 \times 10^{-6} \\
& R_{2}=1 \times 10^{-7}
\end{aligned}
$$

(a) Collision force in different parameters of $R_{2}$ with $R_{1}=5$

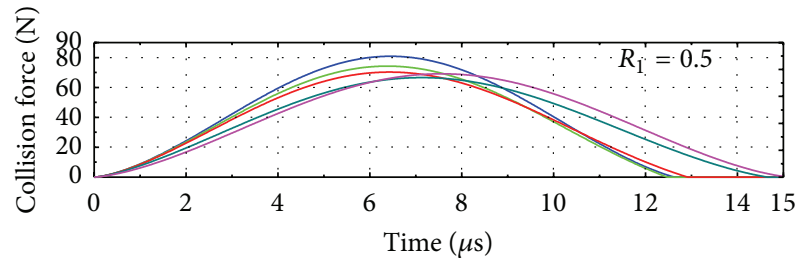

$$
\begin{aligned}
& -R_{2}=1 \times 10^{-4} \\
& -R_{2}=1 \times 10^{-5} \\
& -R_{2}=5 \times 10^{-6} \\
& \begin{array}{l}
R_{2}=1 \times 10^{-6} \\
R_{2}=1 \times 10^{-7}
\end{array}
\end{aligned}
$$

(c) Collision force in different parameters of $R_{2}$ with $R_{1}=0.5$
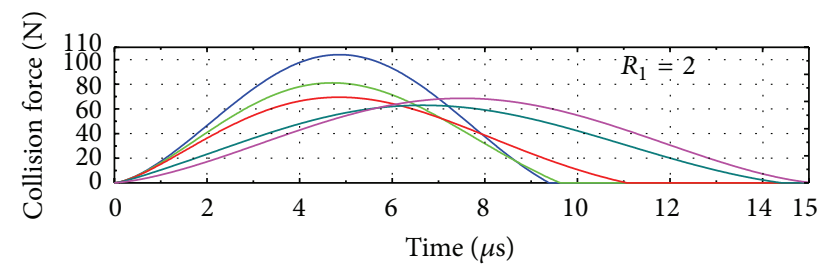

$$
\begin{array}{ll}
R_{2}=1 \times 10^{-4} \\
R_{2}=1 \times 10^{-5} \\
R_{2}=5 \times 10^{-6}
\end{array} \quad-\quad \begin{aligned}
& R_{2}=1 \times 10^{-6} \\
& R_{2}=1 \times 10^{-7}
\end{aligned}
$$

(b) Collision force in different parameters of $R_{2}$ with $R_{1}=2$

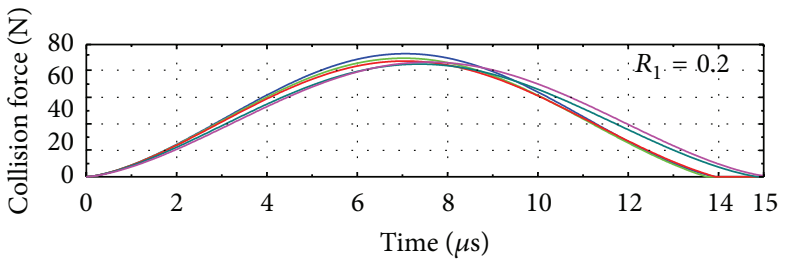

$$
\begin{array}{ll}
-R_{2}=1 \times 10^{-4} \\
R_{2}=1 \times 10^{-5} \\
R_{2}=5 \times 10^{-6}
\end{array} \quad-\quad \begin{aligned}
& R_{2}=1 \times 10^{-6} \\
& R_{2}=1 \times 10^{-7}
\end{aligned}
$$

(d) Collision force in different parameters of $R_{2}$ with $R_{1}=0.2$

FIGURE 8: Collision force influenced by parameters of $R_{2}$ in different $R_{1}$.

can be ignored and only two series of connecting springs are left in the constitutive model.

The influences of $R_{2}$ are shown in Figure 8, in which $R_{1}$ is $5,2,0.5$, and 0.2 , respectively. The variation values for $R_{2}$ is 1 $\times 10^{-4}, 1 \times 10^{-5}, 5 \times 10^{-6}, 1 \times 10^{-6}$, and $1 \times 10^{-7}$. According to Figures $8(\mathrm{a}), 8(\mathrm{~b})$, and $8(\mathrm{c})$, it can be concluded that when the value of $R_{2}$ is smaller, the peak value of collision force firstly decreases and then increases. The larger $R_{1}$ is, the greater the peak values of the curves will be. As $R_{1}$ decreases from 5 to 0.2 , all curves tend to be flat except the one corresponding to $R_{2}=1 \times 10^{-7}$ which remains almost unchanged. When $R_{1}$ is less than 0.2 (Figure $8(\mathrm{~d})$ ), all curves tend to be coincidental with the pink curve (corresponding to $R_{2}=1 \times 10^{-7}$ ). This reason is similar to previous analysis of Figure 7. From (25), when $R_{1}$ is small enough (less than 0.2 in this case), parameter $E_{1}$ in the constitutive model will be much bigger than $C_{1}$. The dash-pot can be ignored, and the whole constitutive model changes to the elastic state again.

4.3. Concrete-to-Concrete Impact. The second example is the collision between concrete-to-concrete, which was carried out by van Mier et al. [35] in 1991. He utilized a concrete striker to hit one end of a long concrete pole and obtained a series of force-time curves for different striker masses and velocities. In most cases, the concrete of striker head involves plastic failure, which can be recognized by the step in forcetime curve. The curves with obvious peak at lower velocity are selected as an example $(57 \mathrm{~kg}, 1.5 \mathrm{~m} / \mathrm{s})$. This example was also calculated by Jankowski [29] in 2005.

The same simplified approach as that in the previous example is utilized to reduce three parameters to two parameters in pounding force model so as to optimize the model

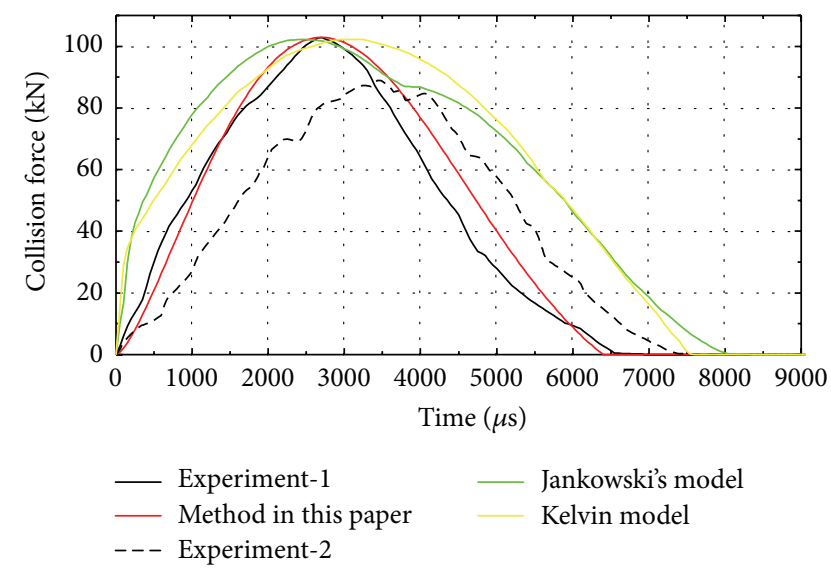

FIGURE 9: Collision force-time histories of concrete-to-concrete (velocity $1.5 \mathrm{~m} / \mathrm{s}$ ).

parameters. However, it is discovered that the fitting curve with the same peak value as the experimental result cannot be obtained by adjusting parameters $R_{1}$ and $R_{2}$. This is because that although there is a peak in experimental curves, the plasticity and damage did occur during the pounding process. Therefore, the third parameter $E_{0}$ must be considered, which represents the equivalent modulus of elasticity in static state. Afterwards, the curve is fitted with the first experimental result manually, and the fitting results are shown in Figure 9, in which $E_{1}=E_{2}=3.2 \times 10^{10} \mathrm{~Pa}, C_{1}=3.2 \times 10^{10} \mathrm{~Pa}$. It can be found that the relative error of the fitting curve is $12.5 \%$, which is smaller than $22.9 \%$ of Jankowski's model and $23.8 \%$ of the linear viscoelastic model (Kelvin model). 


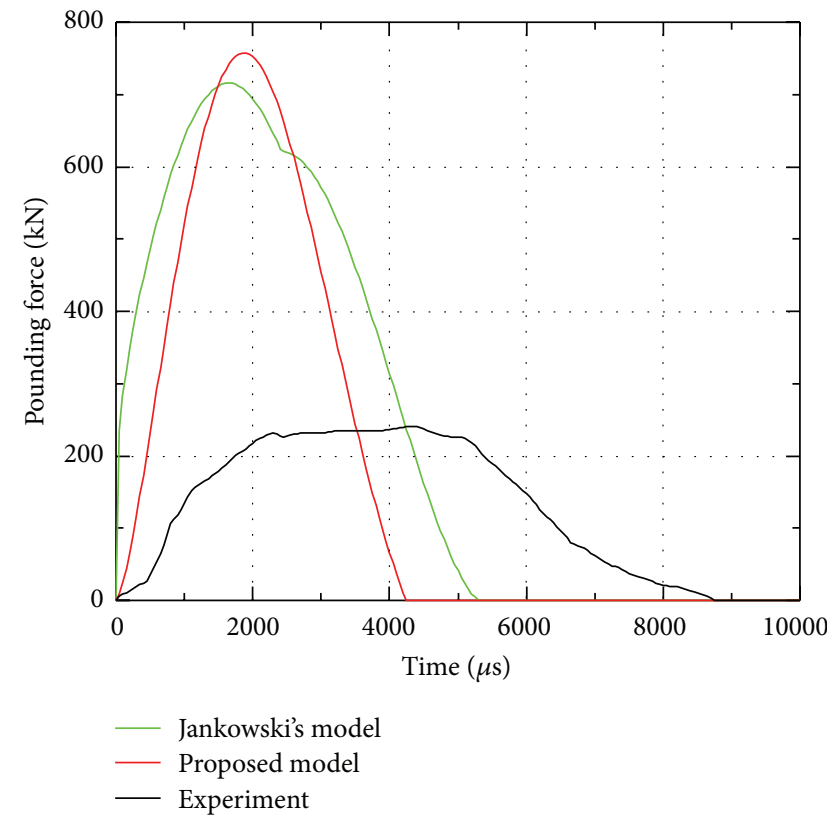

(a) Comparisons between different models in concrete-to-concrete collision

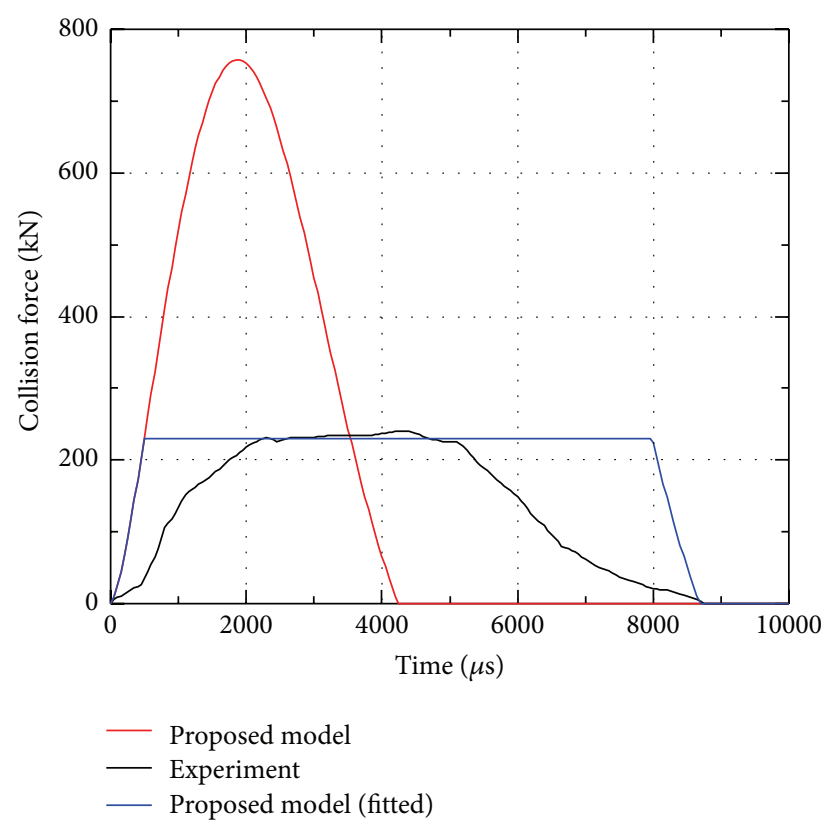

(b) Plateau fitted curve for the proposed model

FIGURE 10: Concrete pounding calculation results with initial velocity of $2.5 \mathrm{~m} / \mathrm{s}$.

In the previous fitting process of concrete-to-concrete pounding force models, the applicability for these 3 parameters in real practice must be studied. Curves in Figure 10 are the concrete pounding calculation results with the initial velocity of $2.5 \mathrm{~m} / \mathrm{s}$.

As shown in Figure 10, it is found that not only the model proposed in this paper but also Jankowski's model has great errors in peak values (Figure $10(\mathrm{a})$ ), which are $227.5 \%$ and $209.4 \%$, respectively. Because the plasticity and damage occur during the collision process, the experimental curve has a significant plateau. It is assumed that when the value of the pounding force calculation of the proposed model is the same as that of the plateau, the curve will be flat until the area under the curve is same with the original calculated results. The fitted curve (blue line) is shown in Figure 10(b). It can be discovered that the ending time of the fitted curve and experimental results is basically the same. The surrounding area difference between these two curves is the momentum loss from the pounding process, which comes from the energy absorption induced by plasticity and damage in concrete colliding bodies. According to the analysis, it can be concluded that all of these pounding models, which are based on elastic or viscoelastic analysis, cannot be utilized in the pounding cases with obvious plasticity or damage.

\section{Vibration Control Application of Proposed Method}

5.1. Pounding Force Model of Pounding TMD. An analysis example is introduced to illustrate the process of constructing a pounding force model. Pounding tuned mass damper (PTMD) is a new type of vibration control device [20,
36 , 37] based on traditional tuned mass damper (TMD). An additional pounding constrain device which is covered by polymers is incorporated to dissipate the energy from deformation of polymers in the collision process.

Figure 11 is the sketch of pounding TMD utilized in signal pole vibration control. In order to analyse the vibration characteristics of this device, the pounding force model needs to be constructed.

The following is the process to construct the pounding model by utilizing the above method. The collision between steel beam and polymer ring can be simplified as a cylinder contacting a plane with curvature. According to contact mechanics [34], when the thickness of polymer ring is larger than a certain extent, the equation of elastic pounding force between two contact bodies can be written as follows:

$$
\begin{aligned}
F_{c} & =\frac{\pi}{4} E^{*} l \delta, \\
\frac{1}{E^{*}} & =\frac{1-v_{p}^{2}}{E_{p}}+\frac{1-v_{s}^{2}}{E_{s}},
\end{aligned}
$$

where $v_{p}, v_{s}, E_{p}$, and $E_{s}$ are the Poisson's ratio and modulus of elasticity for polymer and steel, respectively, $l$ is the width of ring, and $\delta$ is the penetration displacement.

In the case of polymer contact with steel, the modulus of elasticity of steel is far larger than that of polymer. Therefore, the expression of $E^{*}$ can be simplified as

$$
E^{*}=\frac{E^{p}}{1-v_{p}^{2}} .
$$




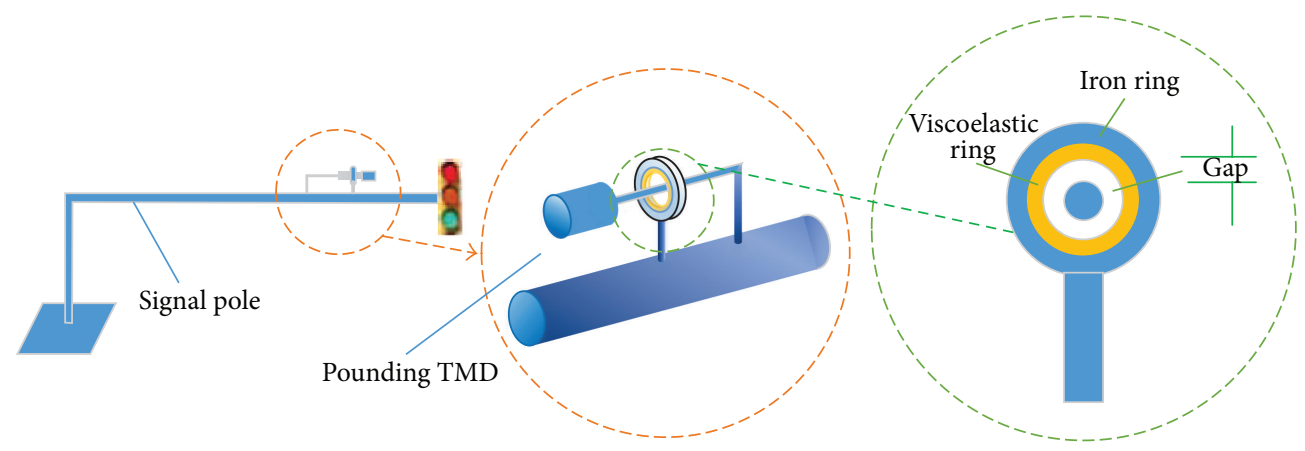

FIGURE 11: Pounding TMD device.

The expression of pounding force is

$$
F_{c}=\frac{\pi}{4} \frac{l}{1-v_{p}^{2}} E_{p} \delta .
$$

For a certain range of strain rate for polymer, Poisson's ratio can be assumed as a constant. When the viscoelasticity of polymer is considered, the same expression in Laplace domain can be achieved according to the Correspondence Principle of Viscoelasticity:

$$
\bar{F}(s)=\left(\frac{\pi}{4} \frac{l}{1-v_{p}^{2}}\right) \overline{E_{p}}(s) \bar{\delta}(s) .
$$

Based on the above analysis, for viscoelastic properties of polymers,

$$
\bar{E}(s)=\frac{\bar{\sigma}(s)}{\bar{\varepsilon}(s)}=\frac{\bar{Q}(s)}{\bar{P}(s)} .
$$

By inversing Laplace transformation in both sides of (30), expression of pounding force considering viscoelasticity of materials can be achieved:

$$
F(t)=\left(\frac{\pi}{4} \frac{l}{1-v_{p}^{2}}\right) \mathscr{L}^{-1}\left(\frac{\bar{Q}(s)}{\bar{P}(s)}\right) \delta(t) .
$$

For linear viscoelastic materials, $\bar{Q}(s)$ and $\bar{P}(s)$ are polynomial of $s$ and they are governed by the constitutive model shown in (31). For some software, such as MATLAB SIMLINK, transfer function instrument can replace the inverse Laplace transformation directly. In addition, it is suitable for different linear constitutive models of viscoelastic materials. As for more complicated linear constitutive models, only the sections of polynomials will change.

5.2. Vibration Control Simulation for Pounding TMD. Li et al. [20] carried out a vibration control study on signal pole with pounding TMD. Viscoelastic tapes VHB4936, which made by $3 \mathrm{M}$ Company, are made into a ring as pounding damper. The experimental model and fitting curves are shown in Figure 12. The pounding TMD is made up by two steel rods, the diameter of which is $12 \mathrm{~mm}$. The first experiment is to put the lateral rod pounding the constrain device (Figure 12(b)).
In Figure 12(a), the black curve is the pounding experiment result, and the green curve is the fitting curve of Jankowski's model in literature [20], in which fitting criterion is not the same peak value but the minimum error defined by (20)-(21). The red curve is the fitting result in the proposed model, in which $E_{0}=0.6 \mathrm{MPa}, R_{1}=0.5$, and $R_{2}=0.01$. The errors of Jankowski's model and the proposed model are $23.4 \%$ and $16.6 \%$, respectively.

In order to investigate the validity of the proposed method, the pounding TMD is simulated and compared with the experiments based on literature [20]. For the pounding TMD model shown in Figure 13, literature [20] simplifies the model to double-spring-oscillator model, which is shown in Figure 13(b). $m_{1}, m_{2}, k_{1}, k_{2}, c_{1}$, and $c_{2}$ are masses, rigid toughness, and damping coefficients for experimental traffic pole model and the pounding TMD device, respectively. They can be deduced from the FEM models analysis and resonant vibration tests results in literature [20].

$x_{1}$ and $x_{2}$ are the displacements of two colliding bodies, and the gap is the distance between L-shaped beam and fixed aluminium ring on traffic pole model with viscoelastic tapes. Therefore, the pounding force $f(t)$ between two oscillators can be illustrated as the following formula:

$$
\begin{aligned}
& f(t)=F(t) x_{2}-x_{1} \geq \text { gap }, \\
& f(t)=F(t) x_{2}-x_{1} \leq- \text { gap }, \\
& f(t)=0, \quad-\text { gap } \leq x_{2}-x_{1} \leq \text { gap. }
\end{aligned}
$$

The vibration equations can be written as follows:

$$
\begin{aligned}
& m_{1} \ddot{x}_{1}+c_{1} \dot{x_{1}}+k_{1} x_{1}-k_{2}\left(x_{2}-x_{1}\right)-c_{2}\left(\dot{x}_{2}-\dot{x_{1}}\right) \\
& \quad=f(t), \\
& m_{2} \ddot{x}_{2}+c_{2}\left(\dot{x_{2}}-\dot{x_{1}}\right)+k_{2}\left(x_{2}-x_{1}\right)+f(t)=0 .
\end{aligned}
$$

The free vibration simulation for pounding TMD is carried out and compared to the experiment in Figure 14. According to the experimental configuration in literature [20], in which the first-order dominant frequency of the experiment model is $3.03 \mathrm{~Hz}$, damping ratio is $1 \%$, and the mass at the end of pounding TMD is $3.7 \mathrm{lbs}$. In this simulation, $m_{1}=20 \mathrm{~kg}, m_{2}=1.67 \mathrm{~kg}, k_{1}=7248.9 \mathrm{~N} / \mathrm{m}$, $k_{2}=592.9 \mathrm{~N} / \mathrm{m}, c_{1}=7.615 \mathrm{~N} \cdot \mathrm{s} / \mathrm{m}$, and $c_{2}=0.6312 \mathrm{~N} \cdot \mathrm{s} / \mathrm{m}$. 

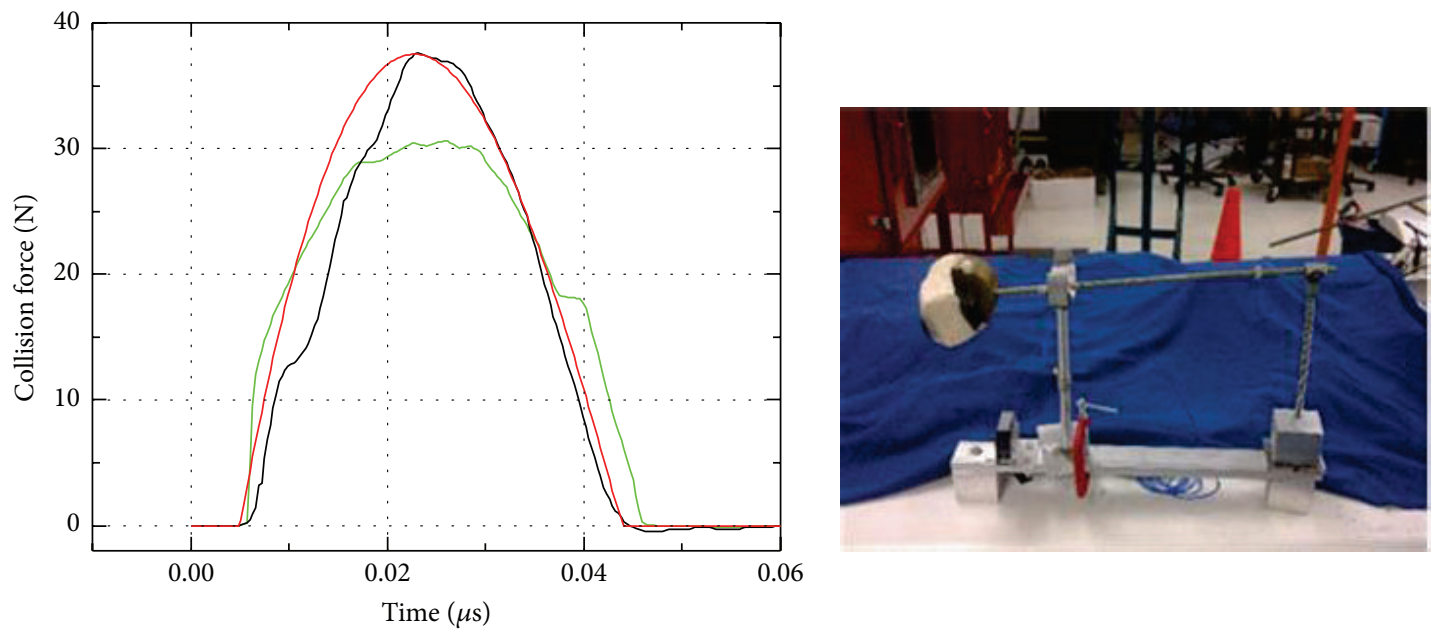

_ Jankowski's model fitting results

- Experiment results

_ Fitting results with proposed model

(a) Fitting curves in different models

(b) The experiment model of pounding TMD [20]

FIgURE 12: Pounding TMD experimental configuration and fitting curves by different methods.

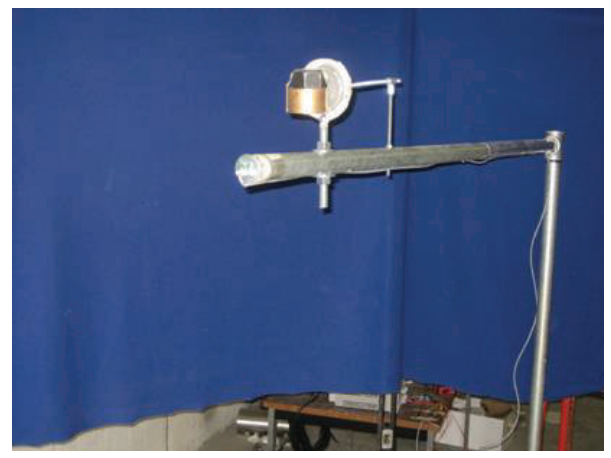

(a) Traffic pole with pounding TMD [20]

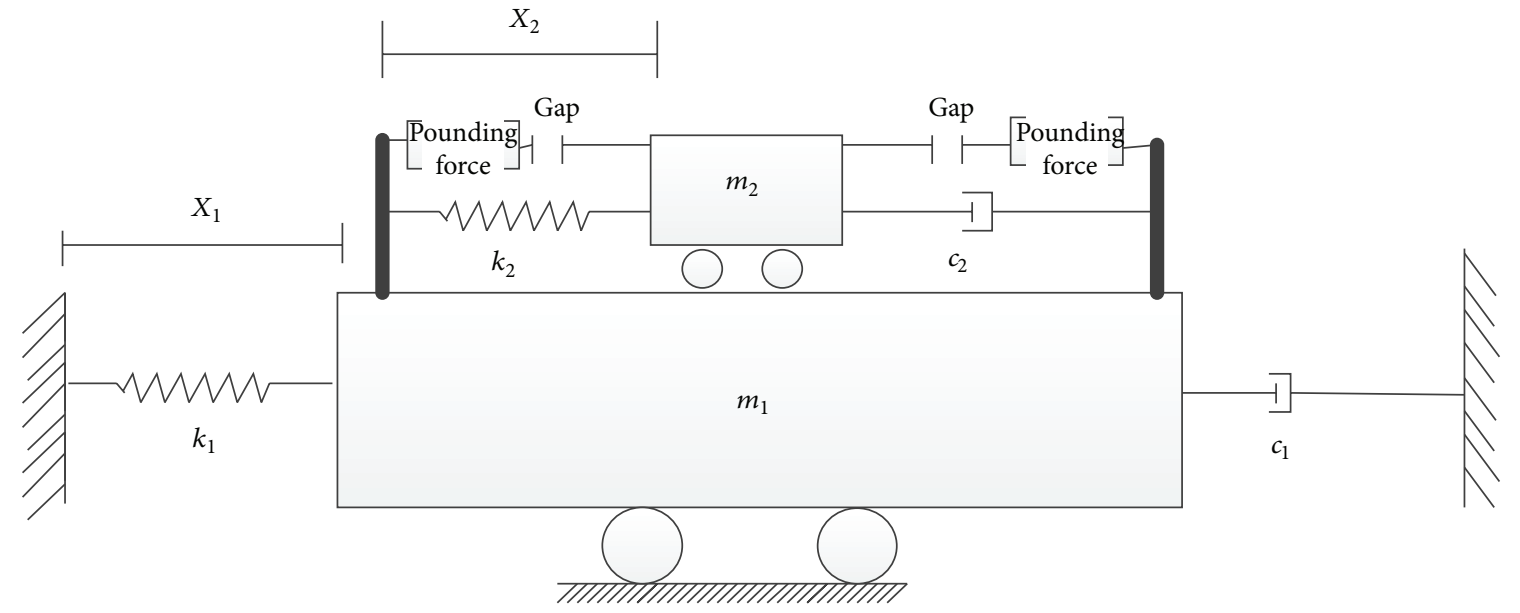

(b) Simplified pounding analysis model

Figure 13: Traffic pole device and simplified pounding TMD model. 


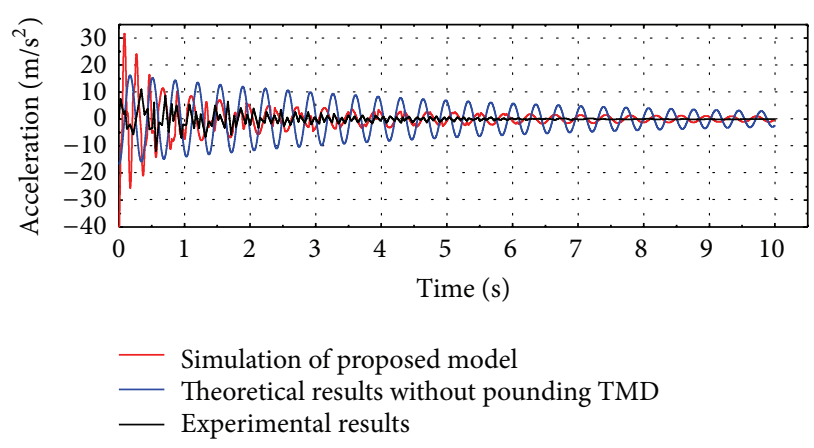

(a) Acceleration results for simulation and experiments

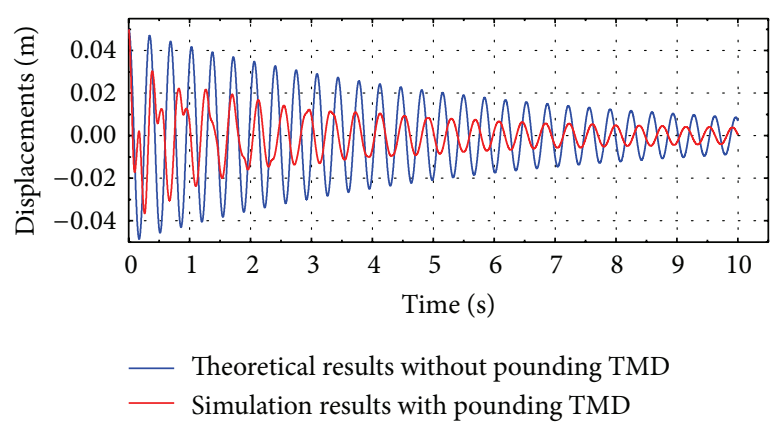

(b) Displacement results of simulation with pounding TMD and theoretical results without pounding TMD

FIGURE 14: Comparisons of acceleration and displacements for simulation and experiments.

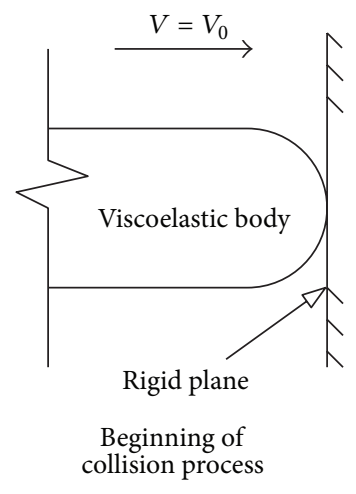

Beginning of
collision process

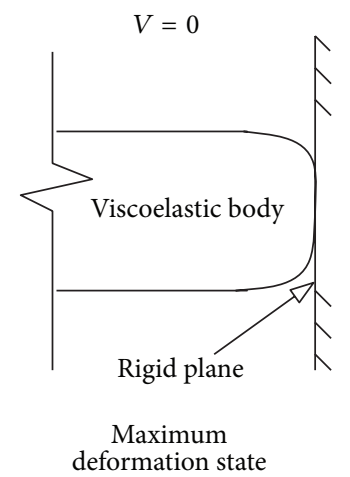

deformation state

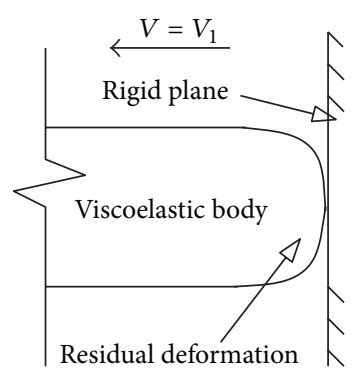

Beginning of

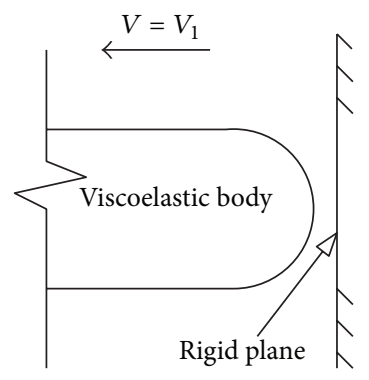

Complete

recovery state

FIGURE 15: Collision process for viscoelastic materials.

The values of gap and widths which are omitted in literature [20] are assumed as $2 \mathrm{~cm}$ and $0.3 \mathrm{~cm}$, respectively. The initial displacement applied to the system is $5 \mathrm{~cm}$.

Figure 14(a) is the comparisons of acceleration in simulation and experiments. The blue curve is the theoretical result without pounding TMD. Black curve and red curve are experimental result and simulation result with pounding TMD, respectively. It is found that both the black curve and red curve show the effectiveness of pounding TMD on vibration control, particularly the acceleration suppression. In the initial section, although the value of acceleration in simulation result is much larger than experimental vibration response without pounding TMD, the displacement of the system with pounding TMD (shown in Figure 14(b)) decreases more rapidly than that in the system without pounding device. In the latter section, the red curve is also larger than the experimental value and changes to a sinusoidal wave. This is because when the relative displacement of pounding TMD main model beam is less than the value of the gap, there will be no collision between them and the whole model will vibrate in a way without pounding effect. In Figure 14(b), the response of displacement for simulation model with pounding TMD shows the effectiveness of pounding TMD, and, in the terminal section, the curve changes to sinusoidal wave, which is the same with Figure 14(a). There is a certain error between simulation and experimental results. The reason is that several parameters of experiment details cannot be precisely determined from insufficient literature details.

Therefore, the proposed model can only illustrate a rough trend in both single pounding process and vibration control process. The study in this paper presents only a firststep assessment, and further numerical and experimental validations are needed in inelastic pounding process.

\section{Discussion and Conclusion}

6.1. Discussion. In the calculation results of different pounding force models, some of them have traction effect at the end of pounding process, such as linear viscoelastic model, nonlinear viscoelastic model, and 3-parameter model of this paper (the traction has been removed). They all contain damper (dash-pot) in the constitutive model. The existence of damper leads to a delay of material recovery to the original position, which means two colliding bodies begin to separate at the end of restitution process. However, residual deformation still exists and it can bounce back after certain time (Figure 15).

When the pounding force is simulated by utilizing different pounding force models, there is an implicit hypothesis that the full recovery of deformation for colliding bodies occurs concurrently with the separated state. Therefore, for all elastic models, including linear and nonlinear elastic models, the hypothesis is tenable. Nevertheless, as for models with 
dash-pot part, separation occurs before the colliding body reaches the complete recovery state, and the traction forces will be deduced at the end of restitution section.

The traction force in the calculation models does not exist in reality, and it has been removed in simulation in the former calculation results. It will affect the calculation results significantly and may cause the divergence in the case of certain set of parameters, especially in the circumstance of extremely little gap values.

6.2. Conclusion. An updated pounding force analysis method based on viscoelasticity of materials is proposed in this paper. Comparisons among proposed pounding force model and other traditional models are analysed. Moreover, the proposed model is applied to simulating the pounding TMD device so as to verify the validity of the model.

The main contribution of the proposed method is that it expands traditional Kelvin viscoelastic model to 3-parameter linear solid viscoelastic model. By utilizing contact mechanics can not only relative parameters be determined but also constitutive model coefficients can be obtained based on the pounding results. For classic elastic collision, the proposed model can also be degenerated or downgraded to represent a linear elastic model to study the pounding process. The feasibility of utilization in different geometric conditions overcomes the shortcoming of classic pounding force models.

Compared with other models, the proposed 3-parameter model for pounding force has shown a certain accuracy in fitting elastic pounding experimental results. However, for plasticity or deformations with damage, such as concrete pounding, it has some limitation in fitting the experiment to a higher precision.

When it is applied in analysis on pounding TMD for vibration control case, there is certain error as compared with the experimental result. However, it has been proved that it can illustrate the changing trend of vibration control process.

The advantage of the method proposed in this paper is that it contains separated parameters of pounding details. What is more, it shows better prospect in calculating polymer materials poundings which have obvious viscoelasticity characteristics. However, it must be noted that the study here is only a first step. Regardless of the cheerful prospect, it still needs a more careful assessment of the model performance, especially in the presence of inelastic response.

\section{Competing Interests}

The authors declare that there are no competing interests regarding the publication of this paper.

\section{Acknowledgments}

The research is supported by the National Natural Science Foundation of China (Project nos. 51678322 and 51409056), Natural Science Foundation of Heilongjiang Province (E2015047), the Fundamental Research Funds for the Central Universities (HEUCF160202), and the Taishan Scholar Priority Discipline Talent Group program funded by the Shan Dong Province.

\section{References}

[1] N. Chouw and H. Hao, "Pounding damage to buildings and bridges in the 22 february 2011 christchurch earthquake," International Journal of Protective Structures, vol. 3, no. 2, pp. 123140, 2012.

[2] G. Mondal and D. C. Rai, "Performance of harbour structures in Andaman Islands during 2004 Sumatra earthquake," Engineering Structures, vol. 30, no. 1, pp. 174-182, 2008.

[3] T. C. Shin, K. W. Kuo, W. H. K. Lee, T. L. Teng, and Y. B. Tsai, "A preliminary report on the 1999 Chi-Chi (Taiwan) earthquake," Seismological Research Letters, vol. 71, no. 1, pp. 24-30, 2000.

[4] Y. Wang, "Lessons learned from the '5.12' Wenchuan Earthquake: evaluation of earthquake performance objectives and the importance of seismic conceptual design principles," Earthquake Engineering and Engineering Vibration, vol. 7, no. 3, pp. 255-262, 2008.

[5] J. Wood and P. Jennings, "Damage to freeway structures in the San Fernando earthquake," Bulletin of the New Zealand Society for Earthquake Engineering, vol. 4, no. 3, pp. 347-376, 1971.

[6] C.-J. Wang and M.-H. Shih, "Performance study of a bridge involving sliding decks and pounded abutment during a violent earthquake," Engineering Structures, vol. 29, no. 5, pp. 802-812, 2007.

[7] R. Jankowski, "Earthquake-induced pounding between equal height buildings with substantially different dynamic properties," Engineering Structures, vol. 30, no. 10, pp. 2818-2829, 2008.

[8] F. Pratesi, S. Sorace, and G. Terenzi, "Analysis and mitigation of seismic pounding of a slender R/C bell tower," Engineering Structures, vol. 71, pp. 23-34, 2014.

[9] K. Shakya and A. C. Wijeyewickrema, "Mid-column pounding of multi-story reinforced concrete buildings considering soil effects," Advances in Structural Engineering, vol. 12, no. 1, pp. 7185, 2009.

[10] P. C. Polycarpou and P. Komodromos, "Earthquake-induced poundings of a seismically isolated building with adjacent structures," Engineering Structures, vol. 32, no. 7, pp. 1937-1951, 2010.

[11] K. Ye, L. Li, and H. Zhu, "A modified Kelvin impact model for pounding simulation of base-isolated building with adjacent structures," Earthquake Engineering and Engineering Vibration, vol. 8, no. 3, pp. 433-446, 2009.

[12] L. L. Cui, A. X. Guo, and H. Li, "Investigation of the parameters of hertz impact model for the pounding analysis of highway bridge," Procedia Engineering, vol. 14, pp. 2773-2778, 2011.

[13] H. Yang and X. Yin, "Transient responses of girder bridges with vertical poundings under near-fault vertical earthquake," Earthquake Engineering \& Structural Dynamics, vol. 44, no. 15, pp. 2637-2657, 2015.

[14] E. G. Dimitrakopoulos, "Seismic response analysis of skew bridges with pounding deck-abutment joints," Engineering Structures, vol. 33, no. 3, pp. 813-826, 2011.

[15] B. Shrestha, H. Hao, and K. Bi, "Effectiveness of using rubber bumper and restrainer on mitigating pounding and unseating damage of bridge structures subjected to spatially varying ground motions," Engineering Structures, vol. 79, pp. 195-210, 2014.

[16] J.-H. Won, H.-S. Mha, and S.-H. Kim, "Effects of the earthquake-induced pounding upon pier motions in the multispan simply supported steel girder bridge," Engineering Structures, vol. 93, pp. 1-12, 2015. 
[17] B. Madani, F. Behnamfar, and H. Tajmir Riahi, "Dynamic response of structures subjected to pounding and structuresoil-structure interaction," Soil Dynamics and Earthquake Engineering, vol. 78, pp. 46-60, 2015.

[18] K. Bi and H. Hao, "Numerical simulation of pounding damage to bridge structures under spatially varying ground motions," Engineering Structures, vol. 46, pp. 62-76, 2013.

[19] M. Goland, P. Wickersham, and M. Dengler, "Propagation of elastic impact in beams in bending," Journal of Applied Mechanics, vol. 22, pp. 1-7, 1955.

[20] L. Li, G. Song, M. Singla, and Y.-L. Mo, "Vibration control of a traffic signal pole using a pounding tuned mass damper with viscoelastic materials (II): experimental verification," Journal of Vibration and Control, vol. 21, no. 4, pp. 670-675, 2015.

[21] A. Ruangrassamee and K. Kawashima, "Control of nonlinear bridge response with pounding effect by variable dampers," Engineering Structures, vol. 25, no. 5, pp. 593-606, 2003.

[22] W. Goldsmit, The Theory and Physical Behavior of Colliding Solids, Arnold, London, UK, 1960.

[23] K. T. Chau and X. X. Wei, "Pounding of structures modelled as non-linear impacts of two oscillators," Earthquake Engineering \& Structural Dynamics, vol. 30, no. 5, pp. 633-651, 2001.

[24] C. P. Pantelides and X. Ma, "Linear and nonlinear pounding of structural systems," Computers \& Structures, vol. 66, no. 1, pp. 79-92, 1998.

[25] S. A. Anagnostopoulos, "Pounding of buildings in series during earthquakes," Earthquake Engineering \& Structural Dynamics, vol. 16, no. 3, pp. 443-456, 1988.

[26] S. A. Anagnostopoulos, "Equivalent viscous damping for modeling inelastic impacts in earthquake pounding problems," Earthquake Engineering and Structural Dynamics, vol. 33, no. 8, pp. 897-902, 2004.

[27] V. K. Agarwal, J. M. Niedzwecki, and J. W. van de Lindt, "Earthquake induced pounding in friction varying base isolated buildings," Engineering Structures, vol. 29, no. 11, pp. 2825-2832, 2007.

[28] P. Komodromos, "Simulation of the earthquake-induced pounding of seismically isolated buildings," Computers \& Structures, vol. 86, no. 7-8, pp. 618-626, 2008.

[29] R. Jankowski, "Non-linear viscoelastic modelling of earthquake-induced structural pounding," Earthquake Engineering and Structural Dynamics, vol. 34, no. 6, pp. 595-611, 2005.

[30] R. Jankowski, "Analytical expression between the impact damping ratio and the coefficient of restitution in the non-linear viscoelastic model of structural pounding," Earthquake Engineering \& Structural Dynamics, vol. 35, no. 4, pp. 517-524, 2006.

[31] R. Jankowski, K. Wilde, and Y. Fujino, "Pounding of superstructure segments in isolated elevated bridge during earthquakes," Earthquake Engineering \& Structural Dynamics, vol. 27, no. 5, pp. 487-502, 1998.

[32] S. Mahmoud, "Modified linear viscoelastic model for elimination of the tension force in the linear viscoelastic," in Proceedings of the 14th World Conference on Earthquake Engineering, 2008.

[33] S. Khatiwada, N. Chouw, and J. W. Butterworth, "A generic structural pounding model using numerically exact displacement proportional damping," Engineering Structures, vol. 62-63, pp. 33-41, 2014.

[34] V. Popov, Contact Mechanics and Friction: Physical Principles and Applications, Springer Science \& Business Media, Berlin, Germany, 2010.
[35] J. G. M. van Mier, A. F. Pruijssers, H. W. Reinhardt, and T. Monnier, "Load-time response of colliding concrete bodies," Journal of Structural Engineering, vol. 117, no. 2, pp. 354-374, 1991.

[36] G. B. Song, P. Zhang, L. Y. Li et al., "Vibration control of a pipeline structure using pounding tuned mass damper," Journal of Engineering Mechanics, vol. 142, no. 6, Article ID 04016031, 2016.

[37] C.-C. Lin, J.-F. Wang, and J.-M. Ueng, "Vibration control identification of seismically excited mdof structure-PTMD systems," Journal of Sound and Vibration, vol. 240, no. 1, pp. 87-115, 2001. 


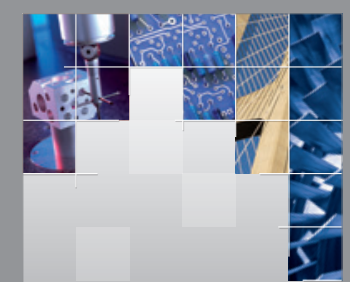

\section{Enfincering}
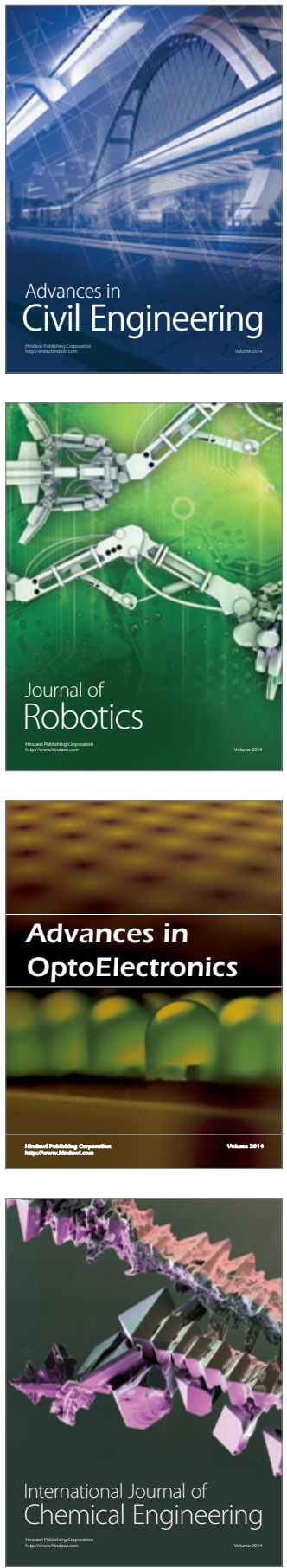

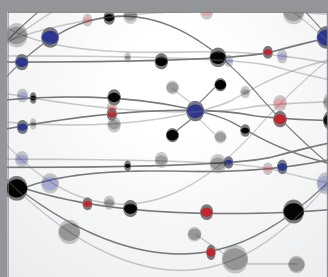

The Scientific World Journal

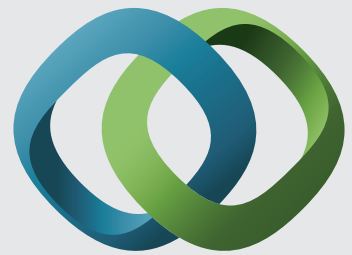

\section{Hindawi}

Submit your manuscripts at

http://www.hindawi.com
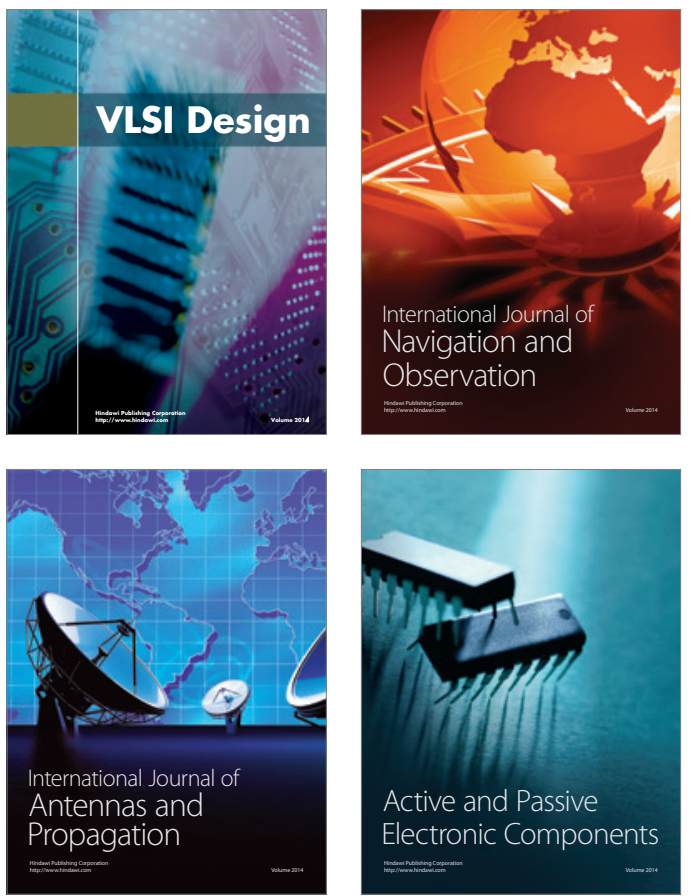
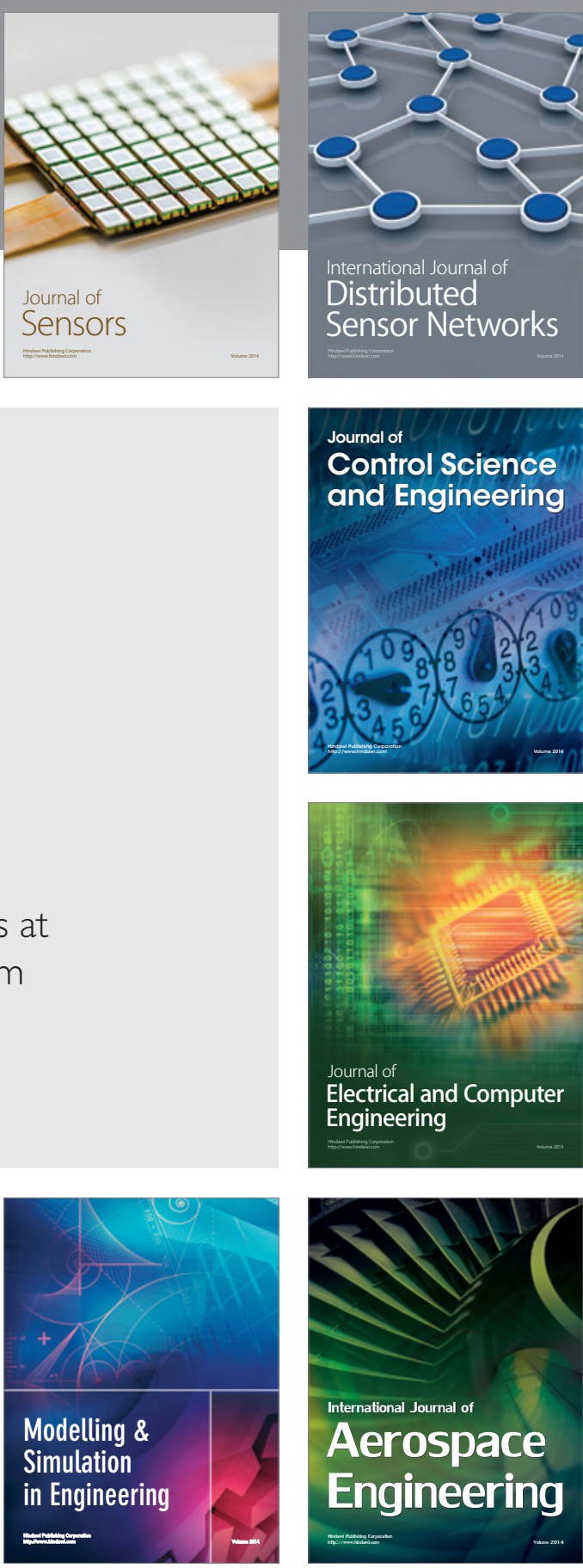

International Journal of

Distributed

Sensor Networks

Journal of

Control Science

and Engineering
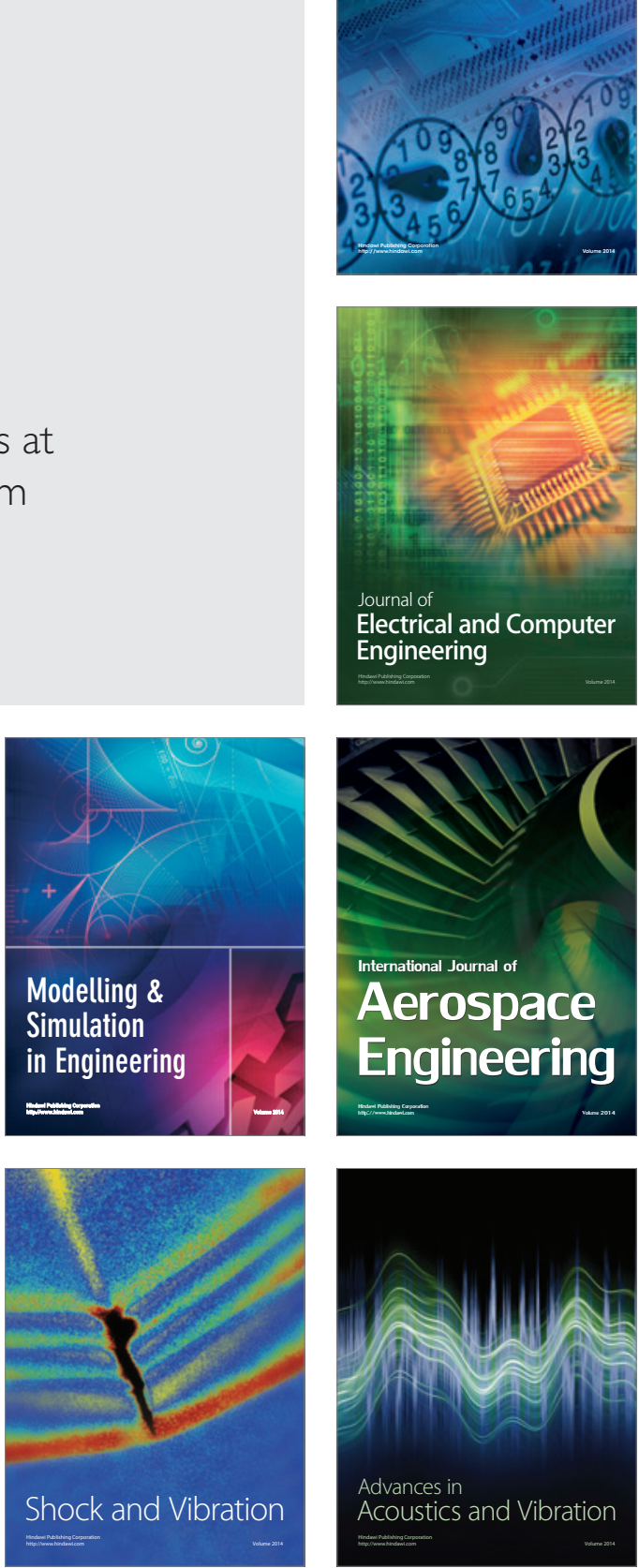